\title{
2D gravity modelling integrated with multi gephysical data to investigate the basement of the southern compartment of Recôncavo basin
}

\author{
Thais da Silva Sales, Rodrigo Bijani, Fernando Freire (Universidade Federal Fluminense, Niterói, Brazil)
}

Copyright 2019, SBGf - Sociedade Brasileira de Geofísica.

This paper was prepared for presentation during the 16th International Congress of the Brazilian Geophysical Society, held in Rio de Janeiro, Brazil, 19 - 22 August, 2019.

Contents of this paper were reviewed by the Technical Committee of the 16th International Congress of The Brazilian Geophysical Society and do not necessarily represent any position of the SBGf, its officers or members. Electronic reproduction or storage of any part of this paper for commercial purposes without the written consent of the Brazilian Geophysical Society is prohibited.

\begin{abstract}
In this study, a bidimensional gravity modelling technique is implemented in Python 2.0, and a bidimensional model is defined by irregular polygons that represent the cristaline basement. Predicted Bouguer anomaly is calculated for the model, also considering that the density contrasts vary in depth on the poligonal model. In order to highlight the residual Bouguer anomaly and compare it with the predicted Bouguer anomaly provided by the method, a polynomial fit were considered and subtracted from the total Bouguer anomaly. With the aim to minimize interpretation ambiguities, log profiles with density information and two seismic lines with details about the basement morphology were required. Two significant results were considered: model 1 , based on multi geophysical data; and model 2, based on previous geological information. In conclusion, the incongruities presented in both models suggest that there are significant heterogeneities on basement's density that results in a negative Bouguer anomaly in a structuraly elevated region.
\end{abstract}

\section{Introduction}

A smoldering interest in the study of sedimentary basins is to determine basement's morfology. One of the most used geophysical method to identify those rocks is gravimetry. Many studies have been developed during the last decades in the Recôncavo in order to reconstruct the story of the basin.

Recôncavo basin is located in the state of Bahia, Brazil, and it is the oldest exploration area in the country. Well-succeeded discoveries in this region motivated the commercial production of petroleum in Brazil in 1941 through Candeias field, which is active until the present day. This basin is classified as mature because of its hydrocarbon exploration and production levels on 21 exploration blocks. Recôncavo basin occupies approximately $12.000 \mathrm{Km}^{2}$ and presents a major orientation NE-SW. Its origin is associated to the opening of South Atlantic ocean, a geotectonic event that happened on Early Cretaceous and its related with the fragmentation of Gondwana. Silva (2007) indicates that the distensive regime produced an aulacogen whose southern part formed Recôncavo basin. This failed arm was filled up with sediments dating from Permian to Neogene, which express the differences in environmental, tectonic and climatic conditions acting during the depositional period (Figure 1).

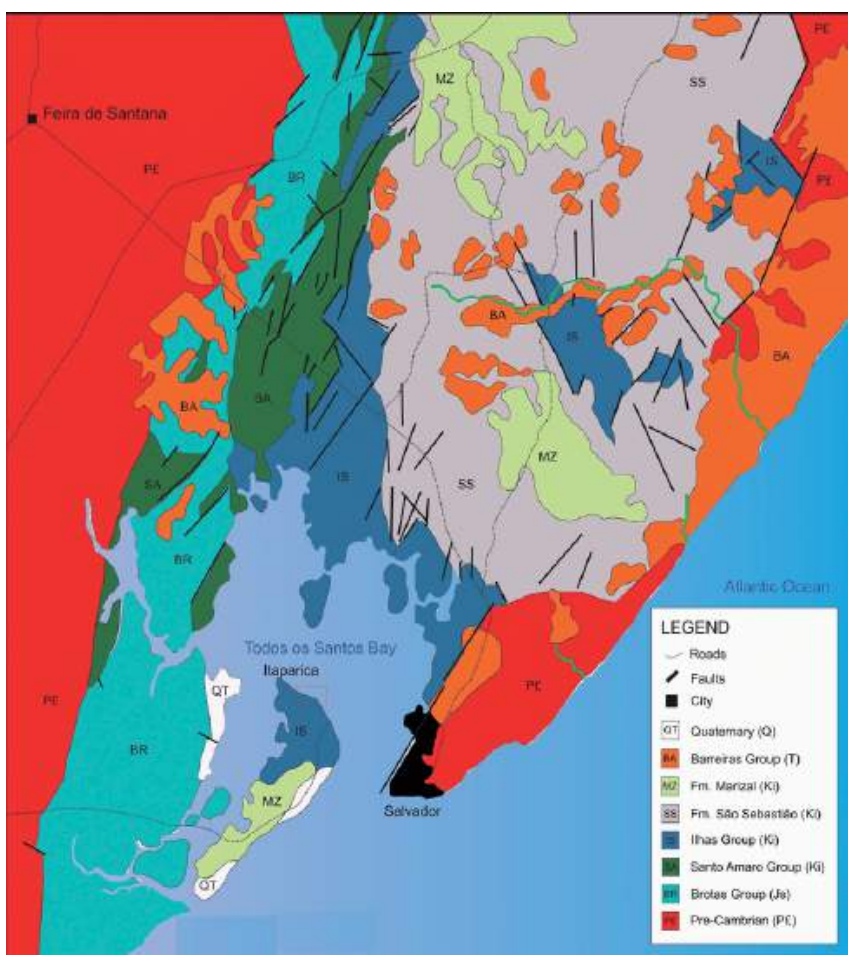

Figure 1: Architecture of Recôncavo basin and its main structural features and sedimentary sequences. From Lima Santos and Correa Gomes (2018).

Recôncavo basin is located over the São Francisco craton, a formation of about 2.0 billion years Alkimin 1993). Mobile belts such as Salvador-Itabuna Curaçá and Salvador-Esplanada, and also the Serrinha Block and the metasedimentary rocks of Estância Group compose the basement underlying the studied basin (Guimarães 2002). It suggests a complex range of physical and geological characteristics on those elements of the basement. Those structures of basement are accommodated by collages that play as weakness zones during further tectonic activities (Figure 2). 


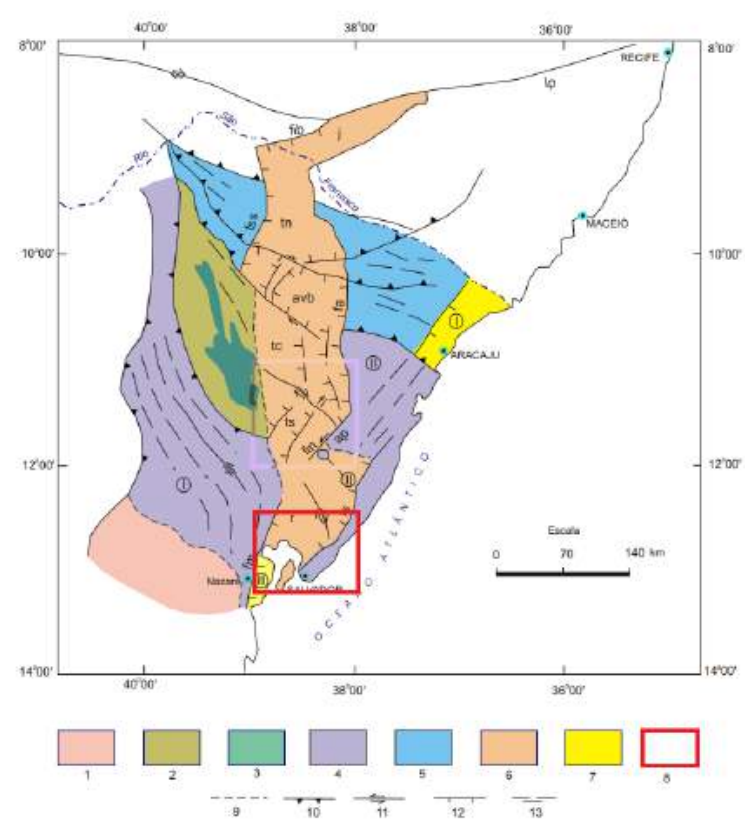

Figure 2: Tectonic scenery of northeastern Brazil. 1: Jequié block; 2: Serrinha Block; 3: Rio Itapicuru Greenstone belts; 4: Mobile belts Salvador-Curaçá (I) and Salvador-Esplanada (II); 5: Sergipan folding zone; 6: Recôncavo-Tucano-Jatobá rift; 7: Sergipe (I) and Camamu (II) basins; 8: Study area; 9: Limits; 10: Compression faults; 11: Transcurrent faults; 12: Normal faults; 13: Strucutural lineaments. Adapted from Guimarães (2002).

The most expressive terrain under Recôncavo basin is Salvador-Esplanada mobile belt. It is formed by gneiss and medium and high-grade migmatites of Arquean and Paleoproterozoic age that were deformed during the Transamazonian cycle. The shear zones that limit the mobile belt also separate its different litologies, thus it generates a differential facies distribution on SalvadorEsplanada belt. Over the occidental region, migmatic orto-gneiss are concentrated while on the oriental region, bimodal orto-gneiss are distributed largely. Essentially, it is considered that Salvador-Esplanada mobile belt is constituted by migmatites, gneiss, granitoids and granulites (Souza-Oliveira et al. 2014).

In order to understand the characteristics of those older and deeper rocks that form the Recôncavo basin, gravimetry is an inderect method of geologic investigation. On the exploration domain, gravity surveys mainly investigate the variations of the gravitational field provoked by the difference of rock densities beneath surface. Theoretically, those density variations occur horizontally and are generated by disturbances on plane-parallel layers of different densities. Structural differences are responsible for the generation of density contrasts (Nettleton 1971).

The resultant density contrast evidences geological situations of interest that can be interpreted as sedimentary basins, salt domes or the basement relief. The interpretation of acquired gravity data adds information about the depth and the shape of the causative body and, also, the comprehension of the associated geological environment.
The reduction fluxogram applied on the observed data highlights its variations, which are classified as gravity anomalies. The Bouguer reduction is a preparation process of data that consists in minimizing the efect caused by the mass excess between the observation station and the reference datum (LaFehr and Nabighian, 2012). For exploration purposes, Bouguer anomaly is the most used because it emphasizes the density contrasts generated by subsurface rocks.

The effect of those anomalies on map is equivalent to the sum of the effect of all masses in the region of study (Nettleton 1971). On one hand, the depper fonts are responsible for the bigger and smooth wavelengths on gravity signal (regional anomaly). On the other hand, the anomalies provoked by shallower sources are more concentrated and accentuated (residual anomalies).

The great economic interest and the established infrastructure in the Recôncavo basin motivate deeper research about the structural and depositional characteristics of the basin with the aim to optimize exploration and production. This study consists on the qualitative and quantitative analysis of data provided by BDEP-ANP in order to define an appropriate basement relief. Firstly, graphical visualizations in Python 2.0 were used to illustrate the distribution of data in the study area. Secondly, data processing were performed to obtain residual Bouguer anomaly and highlight the influence of shallower causative sources. Finally, two different two-dimensional gravity models were proposed through the implementation of the method suggested by Rao et al. (1994). The first model were created based on multi geophysical data analysis and it presented a good adjustment throughout the profile. However, previous works in the study area provided additional geological information that constrained the second model.

\section{Methods}

\section{Regional-residual separation}

The calculation of Bouguer anomaly via polynomial fit consists on solving a linear system in order to obtain the coefficients of the $n^{\text {th }}$ degree polynomial equation. The degree of a polynomial is established by the user, so the adjustment between observed and predicted Bouguer anomaly could be more appropriate. The set of coefficients that better adjust between the polynomial and the observed data were estimated by the linear least squares method:

$$
\mathbf{p}=\left(\mathbf{A}^{T} \mathbf{A}\right)^{-1} \mathbf{A}^{T} \mathbf{d}
$$

where $\mathbf{p}$ represents the parameters (i.e., the coefficients of the polynomial), $\mathbf{d}$ is the total Bouguer anomaly data and $\mathbf{A}$ is the sensibility matrix. The matrix $\mathbf{A}$ is formed by the partial derivatives of the polynomial equation with respect to all the coefficients stored in the vector $\mathbf{p}$. Once the vector $\mathbf{p}$ is obtained, the calculation of regional Bouguer anomaly can be determined by the following expression:

$$
\mathbf{d}(\mathbf{p})=\mathbf{A p} \text {. }
$$

After the application of several degree polynomials, the one that presented a satisfactory result was the $6^{\text {th }}$ degree 
equation. The residual anomaly obtained through this polynomial highlighted the most coherent range of values for Bouguer anomaly in the interest area. Also, it removed the regional trend of the total Bouguer anomaly that were provoked by deep structures (Figure 3.
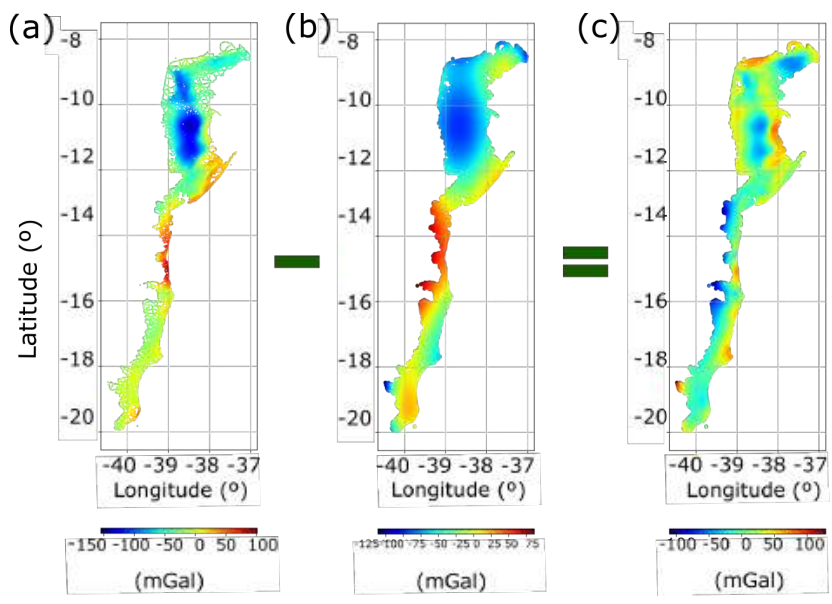

Figure 3: Regional-residual separation. (a) Total Bouguer anomaly is subtracted of (b) Regional Bouguer anomaly calculated by polynomial method. The result of this subtraction is (c) the residual Boguer anomaly.

A function was implemented in Python 2.0 with the aim to calculate Bouguer anomaly on 851 interpolated data points. The resulting profile starts at the flexural edge of the basin and ends at the fault edge. Figure 4 shows the amplitude of residual Bouguer anomaly over the profile. Data amplitudes vary in a -20.0 to 0.0 range. The roughness observed on gravity data may be associated to heterogeneities on the basement caused by differences in lithology or by the presence of tectonic structures such as faults and intrusions.

The modelling method proposed by Rao et al. (1994) was applied to gravity data in order to interpret basement's morfology in the southern compartment of Recôncavo basin. The 2D modelling was realized with the help of an interactive Python 2.0 code. In this method, basement's morfology is simulated by an irregular polygon in which each vertex is determined by the user's clicks.
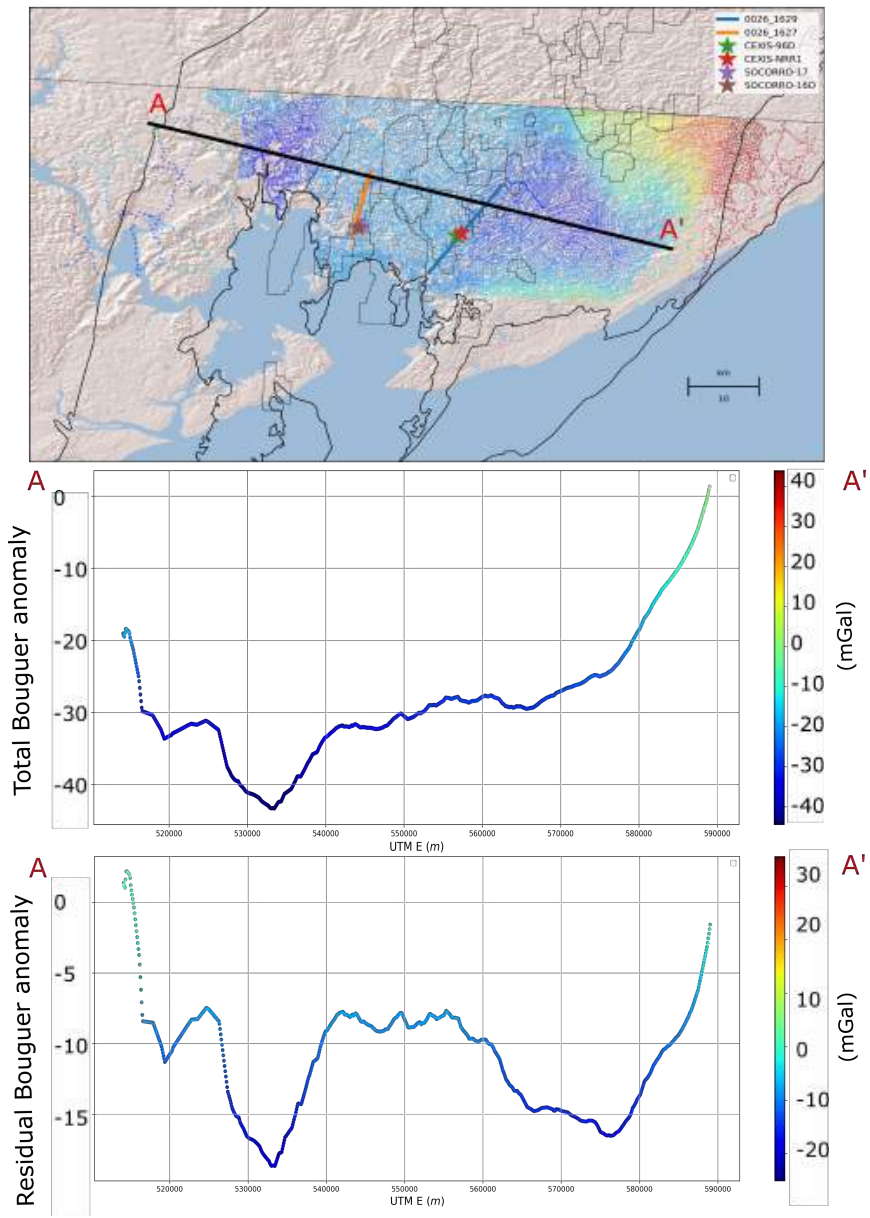

Figure 4: Top: Geographic location of the study area. Middle: Total Bouguer anomaly profile. Bottom: Residual Bouguer anomaly profile.

\section{D gravity modelling}

Rao et al. (1994 method uses a density function that simulates the compaction effect on deposited sediments. In this application, the hyperbolic formulation of the density function was used. This function is described by the equation (Litinsky, 1989):

$$
\Delta \rho(z)=\frac{\Delta \rho_{0} \beta^{2}}{(\beta+z)^{2}}
$$

where $\Delta \rho(z)$ is the density contrast in $z$ depth, $\Delta \rho_{0}$ is the density contrast in the basin surface, and $\beta$ is the density variation rate in length units.

In a surface point $P(0)$, it is possible to calculate the gravity anomaly $\Delta g(0)$ produced by an irregular polygon through the integration of the gravity effect, which is represented by the following expression:

$$
\Delta g(0)=\frac{2 G \int \Delta \rho(z) z d s}{x^{2}+z^{2}}
$$

where $G$ is the universal gravity constant, $\rho(z)$ is the density function, $d s$ is the differential element of the coordinates 
( $d s=d x * d z)$. Subsequentialy, an algebraic manipulation permitted to represent the basement contours by a set of vertex and edges that form a polygon. Thus, the expression turns into:

$$
\Delta g(0)=\sum_{k=1}^{n} d g(k),
$$

where $d g(k)$ is the contribution of the $k^{\text {th }}$ side of the polygon and $n$ is the number of sides. The sum of each $d g(k)$ produces a predicted Bouguer anomaly for each observation point in the interpolated profile.

This method was used to calculate the anomaly on the defined profile. As an additional link, density log profiles and 2D seismic lines provided information about basement's density and depth that were incorporated into the model in order to reduce usual ambiguities on gravity interpretation.

\section{Results}

The integration of geophysical methods (i.e. gravimetry, well $\log$ and seismic) was used cautiously with the aim to reduce inherent ambiguities on gravity modelling. A value of $0.2 \mathrm{~g} / \mathrm{cm}^{3}$ was adopted as the density contrast between the surface rocks and the basement. This value was defined based on density logs near the gravity profile. According to Ramos et al. (2013), the density constrast atributed is consistent with previous analysis. Moreover, the $\beta$ value used to produce the density function was 7.57 , in length units.

The seismic lines 0026-0027 and 0026-0039 were interpreted and they suggest basement depths of $2000 \mathrm{~m}$ and $4000 \mathrm{~m}$, respectively (Figure 5.

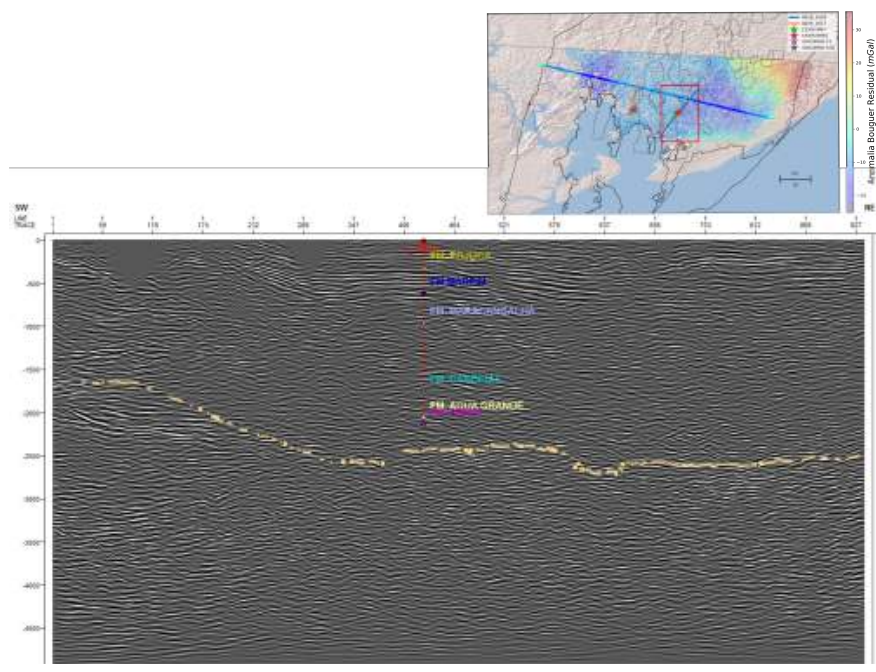

Figure 5: Seismic interpretation of line 0026-0039 in Petrel.

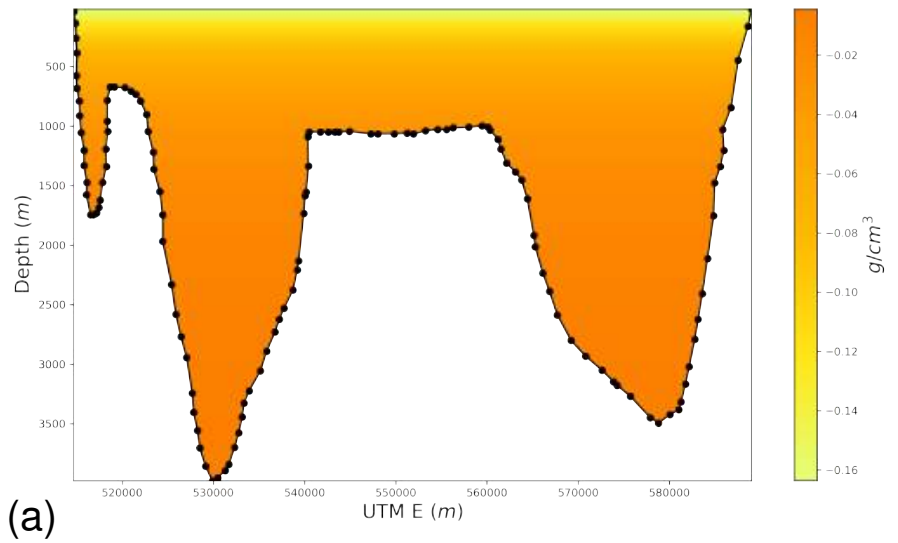

(a)

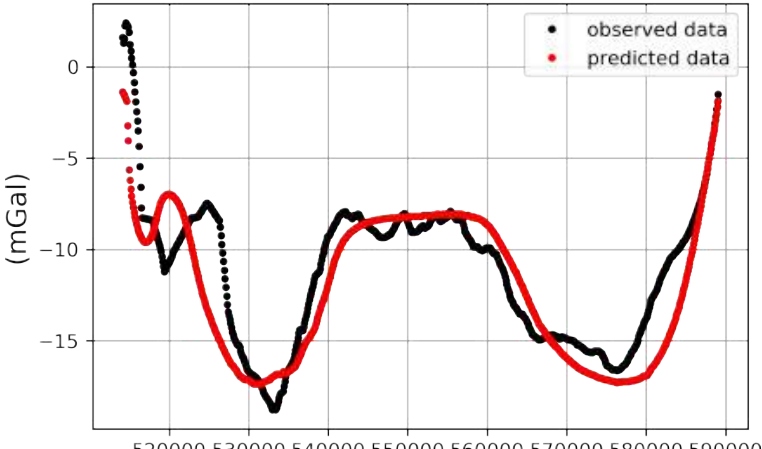

(b)

UTM E (m)

Figure 6: Modelling results obtained through multi geophysical data use.

Considering the limitations of the modelling method used and also the ambiguity associated to geophysical methods, the result presented in Figure 6 is not coherent with previous interpretation of the basement.

The first limitation is atributed to the hyperbolic density function, whereas it presented a significant smoothness and it does not embraces density heterogeneities provoked by different sedimentary layers. The second limitation is the lack of resolution to highlight small scale anomalies, which make this method applicable to the investigation of large tectonic and sedimentary structures. Finally, the biggest limitation of the method is the premise of a homogeneous basement, which culminated in inaccuracies between the defined model and the geological context that is described on several studies, such as Silva Dias et al. (2009).

Silva Dias et al. (2009) contradicts the first model when presenting a structural map of the basement on Recôncavo basin (Figure 7). This map was created through a geometric computacional modelling that was calibrated with data from 100 well logs.

It indicates that the depocenters thickning occurs in NW-SE direction. Based on this analysis, a polygon made by levels from $0 \mathrm{~m}$ to $4000 \mathrm{~m}$ was created (Figure 6. 


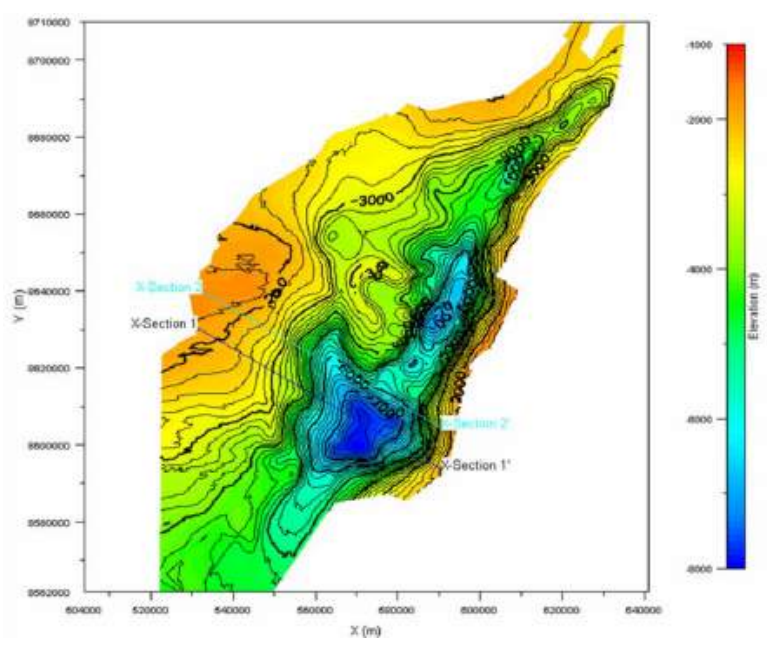

Figure 7: Structural map of the basement of Recôncavo basin. From Silva Dias et al. (2009).

It is notorious that the sinking tendency in the basin is towards the southeastern region, however Silva Dias et al. (2009) does not confirm the presence of a high-magnitude grabens on the northwestern portion, which differs from the adjustment between gravity data in the first model.

After this evaluation and discussion, another modelling was realized based on different physical parameters.

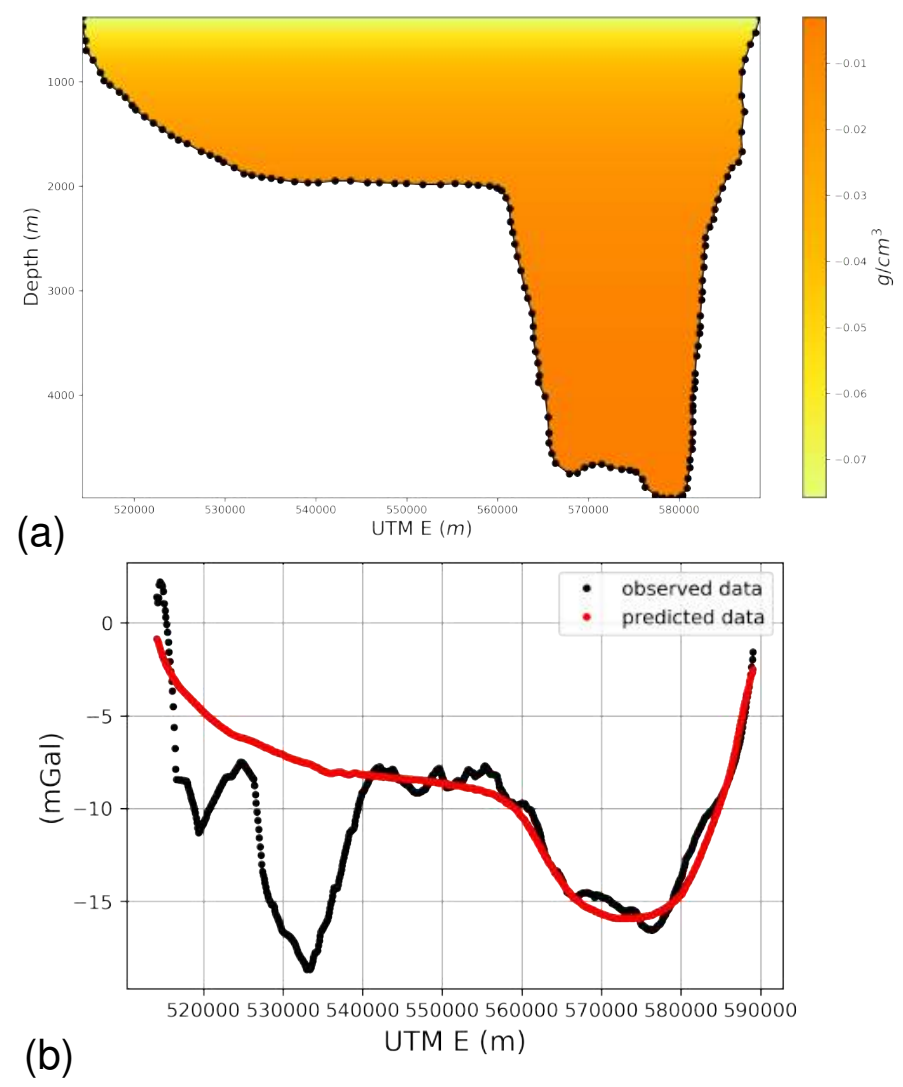

Figure 8: Modelling results obtained through previous geological information.
The result given on Figure 8 indicates some interpretatives possibilities to the geological scenery on the southern portion of Recôncavo basin. Bouguer anomaly responds to density and depth of the causative body. Both characteristics influence the amplitude of the gravity signal showed on Figure 8 (b). The hyperbolic density function incorporated to the modelling forbids the lateral variation of density that is attributed to the sedimentary fill. This effect can be an acceptable justification for the observed misfit on profile's northwestern portion. Nonetheless, profile's southeastern portion presents a satisfactory adjustment with the observed data and agreement with the known geological set.

Initially, it can be considered that the basement presents heterogeneities, with less dense rocks on the northwest and denser rocks on southeast. This perspective explains the negative Bouguer anomaly located between UTM E 530000 and 520000, which is more negative than the Bouguer anomaly observed at the main depocenter of the basin, located between UTM E 580000 and 570000.

According to Silva et al. (2007), the basement of Recôncavo basin is composed by distinct mobile belts that suffered different tectonic processes and also present distinct petrology and mineralogy. Thus, the $-15 \mathrm{mGal}$ response that was obtained on the nortwestern portion on Figure 8 (b) is not necessarily related to a tectonic graben but it can be a consequence of less dense rocks on basement's composition. This conclusion agrees with the ambiguity that is typical on geophysical methods, specially on gravimetry.

\section{Conclusions}

The presented research used a bidimensional gravimetric modelling as a technique to infer basement's morfology in the southern compartment of Recôncavo basin. A gravimetric profile $\mathrm{AA}^{\prime}$ was determined, with orientation NW-SE, in order to understand the internal relief of the basin. The density hyperbolic function simulates the compaction effect on the sedimentary fill that increases with depth, which contemplate the usual dynamics of sedimentary basins. Through the compilation of codes on Python 2.0, two models of basement relief were proposed.

Those models were estimated by multi geophysical data (Model 1) and previous geological information (Model 2). On model 1, the integration of geophysical data allowed to model the basement with a good regional adjustment, mainly for large tectonic and sedimentary structures. However, because of the typical ambiguity on gravimetry, the resulting interpretation about the basement relief presented some incongruities when compared with other studies.

In order to overcome this limitation, model 2 was created based on published studies about the morfology of basement. Thus, a good adjust was obtained on the souteastern portion of the profile, but incompatibilities were observed on the opposite border. The final geological interpretation suggests that density heterogeineities may be found on the basement, which provoke the most negative Bouguer anomaly on the northwestern portion of the gravimetric profile. 


\section{Acknowledgments}

We thank The National Petroleum Agency (ANP) for providing the multi geophysical data used in this project and the companies Schlumberger and GeoEnergy for providing the educational licenses for the softwares Petrel and Interactive Petrophysics, respectively. Also, we thank the group of Integrated Studies of Recôncavo Basin, stablished in the department of Geology and Geophysics at UFF, for motivating this investigation and for sharing knowledge and experience that helped to develop this study.

\section{References}

Alkimin, F., 1993, Arcabouço tectônico do cráton de são francisco, uma revisão: III Simposio do Craton do Sao Francisco, Salvador, 45-62.

Guimarães, J. T., 2002, Projeto bacia do tucano sul.

LaFehr, T. R., and M. N. Nabighian, 2012, Fundamentals of gravity exploration: Society of Exploration Geophysicists.

Lima Santos, N., and L. Correa Gomes, 2018, Study on the gravitational flow directions of the maracangalha formation (early cretaceous), bom despacho, nne area of itaparica island, bahia, brazil: Brazilian Journal of Geology, 48, 503-518.

Litinsky, V., 1989, Concept of effective density: Key to gravity depth determinations for sedimentary basins: Geophysics, 54, 1474-1482.

Nettleton, L. L., 1971, Elementary gravity and magnetics for geologists and seismologists: Society of Exploration Geophysicists.

Ramos, L. C., C. Martins, and J. Silva, 2013, Procedimentos lineares e inversão gravimétrica para estimar o relevo do embasamento de bacias sedimentares: 13th International Congress of the Brazilian Geophysical Society \& EXPOGEF, Rio de Janeiro, Brazil, 26-29 August 2013, Society of Exploration Geophysicists and Brazilian Geophysical Society, 531-536.

Rao, C. V., V. Chakravarthi, and M. Raju, 1994, Forward modeling: Gravity anomalies of two-dimensional bodies of arbitrary shape with hyperbolic and parabolic density functions: Computers \& Geosciences, 20, 873-880.

Silva, O. d., J. Caixeta, P. d. S. Milhomem, and M. Kosin, 2007, Bacia do recôncavo: Boletim de Geociencias da PETROBRAS, 15, 423-431.

Silva Dias, F. J., V. C. Barbosa, and J. B. Silva, 2009, 3d gravity inversion through an adaptive-learning procedure: Geophysics, 74, 19-121.

Souza-Oliveira, J. S. d., J.-J. Peucat, J. S. F. Barbosa, L. C. Correa-Gomes, S. C. P. Cruz, Â. B. M. Leal, and J.-L. Paquette, 2014, Lithogeochemistry and geochronology of the subalkaline felsic plutonism that marks the end of the paleoproterozoic orogeny in the salvador-esplanada belt, são francisco craton (salvador, state of bahia, brazil): Brazilian journal of geology, 44, 221-234. 